\title{
Reading disability and defects of the middle ear
}

\author{
D MURDOCH EATON AND H NOWELL
}

St Mary's Hospital Medical School, London

SUMMARY The impedance bridge test is a sensitive and objective measure of the integrity and function of the middle ear. ${ }^{1}$ Tympanograms obtained from children with a specific reading disability were compared with those from a matched group of controls. A significantly higher prevalence of defects of the middle ear was shown in the test group.

Serous otitis media is a common cause of temporary conductive hearing loss in young children. A considerable body of recent research has implicated conductive hearing loss in language and educational retardation in children of junior school age. ${ }^{2}$

Although this condition usually resolves by the age of 8 years, some children continue to be affected. These are often the children who are said to have normal hearing in studies of reading and learning difficulties. There is no doubt that many children classed as having 'normal' hearing according to existing criteria and procedures have demonstrable defects of the ear.

We sought to establish whether there was a higher than normal prevalence of abnormalities of the middle ear in children with reading disabilities who were attending remedial reading centres. We used the impedance bridge, an apparatus not routinely used in school screening procedures.

\section{Method}

We selected a control group of 59 children from a normal school and a test group of 55 children from remedial reading centres, all within the Inner London Education Authority area. The groups included children from comparable backgrounds. All the children were within the age range 7-11 years, and teachers were asked to rate the intellectual ability of each child on a five point scale. The ethnic group of each child was noted. Testing was carried out within a 6 week period in the spring, well after the peak of mid-winter respiratory disease. All children showing abnormal results underwent otoscopic examination to exclude excessive wax as a possible transient cause.

We used an impedance bridge (1722 Middle Ear Analyser: Grason Stadler) with a probe tone frequency of $220 \mathrm{~Hz}$. The resistance to sound transmission is termed acoustic impedance. An acoustic impedance meter is a device for measuring the amount of sound reflected from the tympanic membrane in response to changes (or compliance) of the middle ear system. When impedance is high, compliance is low. If there is any abnormality in the middle ear-for example, if the middle ear cavity is filled with fluid-movement of the tympanic membrane is reduced. The amount of reflected sound energy is then greater, and less energy is transmitted to the cochlea. In this case, the middle ear is exhibiting high impedance and, therefore low compliance.

Tympanometry is the measurement of changes in compliance in the middle ear system as air pressure is varied in the external meatus. Under normal circumstances the pressure in the middle ear is the same as external ambient pressure. If there is a difference in pressure between the external auditory meatus and the middle ear space the tympanic membrane is made less compliant; the greater the pressure differential on the tympanic membrane, the greater the change in compliance. The changes in compliance that occur with changes in air pressure are plotted on a graph called a tympanogram, which is produced automatically by the impedance bridge.

Tympanograms are interpreted by the analysis of three essential features-namely pressure, amplitude (compliance), and shape. James Jerger was one of the first to describe basic tympanogram curves and relate them to various conditions of the middle ear. The figure shows the three basic curves that he distinguished and classified as types A, B, and C.

Type $\mathrm{A}$ curves are found in patients with normal middle ear function and are characterised by a clearly defined peak representing the point of maximum compliance, which occurs at or near to $0 \mathrm{~mm} \mathrm{H}_{2} \mathrm{O}$ pressure. Pathological conditions that render the tympanic membrane less mobile generally produce type B tympanograms. The type B curve shows little or no change in compliance of the middle 
Type A

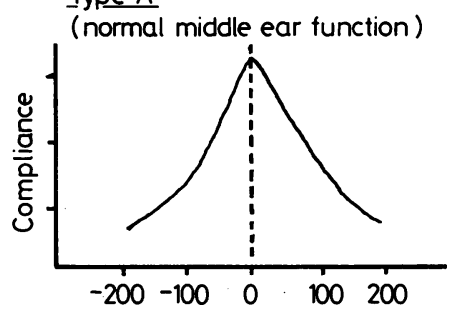

Iype B

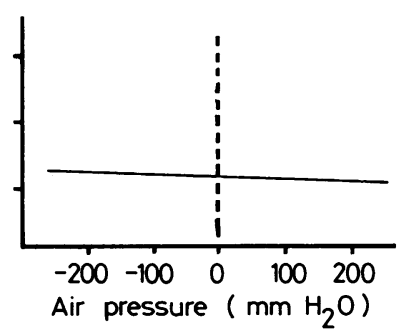

Iype C

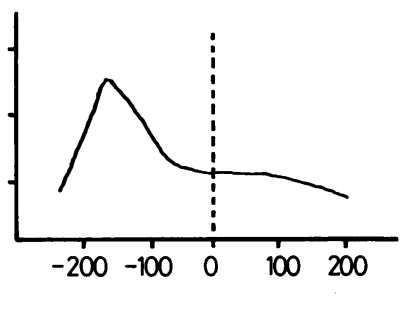

Figure Three tympanograms showing the three basic curve types.

ear as air pressure in the external auditory meatus is varied. Type $B$ is most commonly seen in serous otitis media where fluid is filling the middle ear space. Type $\mathrm{C}$ curve resembles type $\mathrm{A}$, but the peak indicating the point of maximum compliance is shifted to the left of $0 \mathrm{~mm} \mathrm{H}_{2} \mathrm{O}$ pressure. This generally occurs if the eustachian tube is not functioning adequately, thus allowing negative pressure to build up in the middle ear space. The type $C$ pattern is very common, particularly in children; it may indicate a transient condition, and swallowing is often sufficient to open the tube and return the pressure to normal. For the purposes of our study, a type A tympanogram was defined as one in which the peak pressure lay between +100 and $-150 \mathrm{~mm} \mathrm{H}_{2} \mathrm{O}$ and compliance was normal to high $(0 \cdot 2-2 \cdot 5 \mathrm{ml})$. Type $\mathrm{B}$ tympanograms showed a compliance of less than $0.2 \mathrm{ml}$ and type $\mathrm{C}$ tympanograms had a pressure peak greater than $-150 \mathrm{~mm} \mathrm{H}_{2} \mathrm{O}$.

Because middle ear disease precludes changes in tympanic membrane compliance, the acoustic reflex may be expected to be absent in ears with conductive hearing loss. In borderline cases the presence or absence of the reflex constituted a pass or fail. ${ }^{34}$

\section{Results}

The mean age of the children in both groups was 9.5 years (range $7 \cdot 0-11 \cdot 0$ ), and there were no statistically significant differences between the other variables measured (sex, race, and intellectual ability).The Table shows the results of tympanometry.

Abnormal results were seen in four out of 59 $(6.8 \%)$ of the controls, all of whom were affected in one ear only: two showed type B curves and two type $C$ curves. In contrast, abnormal tympanograms were seen in 14 out of $55(25.5 \%)$ of the test group, four of whom were affected in both ears. Of the 10 children who were affected in one ear only, four showed type $B$ curves and 6 type $C$ curves. Of the four test group
Table Numbers of abnormalities detected on tympanograms in the control and test groups

\begin{tabular}{lll}
\hline & \multicolumn{2}{l}{ No $(\%)$ of children with: } \\
\cline { 2 - 3 } & $\begin{array}{l}\text { Normal }(A \text { curve }) \\
\text { tympanogram }\end{array}$ & $\begin{array}{c}\text { Abnormal }(B \text { or C curve }) \\
\text { tympanogram }\end{array}$ \\
\hline Control group $(\mathrm{n}=59)$ & $55(93 \cdot 2)$ & $4(6 \cdot 8)$ \\
Test group $(\mathrm{n}=55)$ & $41(74 \cdot 5)$ & $14(25 \cdot 5)$ \\
\hline
\end{tabular}

$\chi^{2}$ yielded a statistical significance within the 0.02 level.

children affected in both ears, one child showed type B curve tympanograms, two showed type $C$ curves, and one child had one ear showing type $B$ and one ear showing type $\mathrm{C}$ curve. Two of these four children showed speech problems in addition to their reading difficulties: their tympanograms were type B curves. None of these children had had treatment at any time for middle ear problems.

\section{Discussion}

The test group consisted of children attending remedial reading centres within the Inner London Education Authority area. Strict criteria are applied for entry to these classes. Children admitted have specific reading disabilities unrelated to emotional or attendance problems or to adaptation to a second language. Specific reading disabilities are found across a wide range of intellectual abilities, and 'bright' children who are seriously 'underachieving' are also considered for these classes. Unless it is specifically requested, these children receive no additional audiological assessment.

The prevalence of middle ear defects detected in our control group correlates well with other studies, which have given $6.5 \%$ as the prevalence in a normal population. ${ }^{5}$ The significantly higher proportion found in the children attending remedial reading centres suggests a possible correlation between middle ear pathology and reading difficulties. It is 
probably not as simple as a direct causal relationship; there is, however, the speculation that conductive hearing problems are an aetiological factor in reading disability. ${ }^{6}$ As conductive hearing loss can be treated ${ }^{7}$ children with specific reading disabilities should undergo regular audiological assessment.

\section{References}

1 Renvall U, Liden G. Screening procedure for detection of middle ear and cochlear disease. Ann Otol Rhinol Laryngol [Suppl] 1980;89:214-6.

2 Penniceard RM, Rabinowitz A. Educational retardation and conductive hearing problems. 2nd edition. London: ILEA Schools Psychological Services, 1981.

3 Northern JL. Impedance screening - an integral part of hearing screening. Ann Otol Rhinol Laryngol [Suppl] $1980 ; 89: 233-5$.

4 Goodall LM, Bradford PJ, Bulteau V, Upfold L. What is impedance audiometry. Med J Aust 1980;2:545-8.

5 Liden G, Renvall U. Impedance and tone screening of schoolchildren. Scand Audiol 1980;9:121-6.

6 Holm VA, Kunze LH. Effect of chronic otitis media on language and speech development. Pediatrics 1969;43: 833-9.

7 Lampe RM, Weir RR, McLeod H, Aspinall K, Artalejo L. Tympanometry in acute otitis media-prognostic implications. Am J Dis Child 1981 ;135:233-5.

Correspondence to D Murdoch Eaton and $\mathbf{H}$ Nowell, c/o Department of Paediatrics, St Mary's Hospital Medical School, London W2 1PG.

Received 12 August 1983 